TITLE:

\title{
Integrating Fuel Cell/Electrolyzer/Ultracapacitor System Into a Stand-Alone Microhydro Plant
}

\author{
$\operatorname{AUTHOR}(\mathrm{S})$ : \\ Gyawali, Netra; Ohsawa, Yasuharu
}

\section{CITATION:}

Gyawali, Netra ...[et al]. Integrating Fuel Cell/Electrolyzer/Ultracapacitor System Into a Stand-Alone Microhydro Plant. IEEE Transactions on Energy Conversion 2010, 25(4): 10921101

\section{ISSUE DATE:}

2010-12

URL:

http://hdl.handle.net/2433/135443

\section{RIGHT:}

c 2010 IEEE. Personal use of this material is permitted. Permission from IEEE must be obtained for all other uses, in any current or future media, including

reprinting/republishing this material for advertising or promotional purposes, creating new collective works, for resale or redistribution to servers or lists, or reuse of any copyrighted component of this work in other works. 


\title{
Integrating Fuel Cell/Electrolyzer/Ultracapacitor System Into a Stand-Alone Microhydro Plant
}

\author{
Netra Gyawali, Student Member, IEEE, and Yasuharu Ohsawa, Member, IEEE
}

\begin{abstract}
This paper explores the control and operational aspects of introducing fuel cell/electrolyzer/ultracapacitor (FC/ELZ/UC) unit into a microhydro power system, replacing the conventional electronic load controller/dump-load unit. FC/ELZ is expected to provide long-term energy balance by utilizing the hydrogen technology, whereas the UC is employed as buffer storage for the transient compensation. System configuration is proposed, control scheme is designed, and the detailed dynamic modeling is developed for each component of the system. Expected behaviors during the sudden load change and hydro input variation are observed by mathematical simulation. Finally, the results of the analysis are summarized with their applicability to real system and the limitation/further scope are indicated.
\end{abstract}

Index Terms-Converters, electrolyzer (ELZ), energy storage, fuel cells (FCs), microhydro, renewable sources, stand-alone system, ultracapacitor (UC).

\section{INTRODUCTION}

$\mathbf{R}$ ISING environmental concerns, increasing fossil-fuel depleting rate, and the recent advent of power electronics technology are favoring the deployment of renewable type distributed generation (DG) units around the world. In rural and remote areas, the DG has drawn further attention for the standalone operation due to the high cost and complexity of transmission network. Subject to availability, microhydro power (MHP) system is very attractive among the renewable sources, owing to its mature technology, minimum civil work, and cheap installation cost. In many developing countries, the MHP systems are located in remote area and operated in stand-alone mode, therefore, the robust and reliable technology manageable by the local people is required, which applies for the choice for the controller, generator, and turbine technologies. Pelton wheel with cross flow turbine as a prime-mover and squirrel-cage induction generator (IG) as electromechanical power converting medium, is quite popular due to simple and robust technology. Having lacked the large pond storage, the MHP system is regarded as the nondispatchable generating unit. Further, due to the small size of generator $(<100 \mathrm{~kW})$, the governor action is not incorporated making the free flow of water to hit the turbine. In such case, the MHP designers have been adopting the electronic load

Manuscript received July 25, 2009; revised April 6, 2010 and June 5, 2010; accepted July 13, 2010. Date of publication September 20, 2010; date of current version November 19, 2010. Paper no. TEC-00301-2009.

The authors are with the Department of Electrical Engineering, Kyoto University, Kyoto 615-8510, Japan (e-mail: gyawali.n@ax2.ecs.kyoto-u.ac.jp; ohsawa@kuee.kyoto-u.ac.jp).

Color versions of one or more of the figures in this paper are available online at http://ieeexplore.iee.org.

Digital Object Identifier 10.1109/TEC.2010.2066977 controller (ELC) and dump load to balance the power against the varying load [1]-[4]. An ELC is a power electronics system, either IGBT/thyristor switches feeding ac load [4] or the rectifierchopper feeding dc load [1]-[3], allowing designated current flow through the dump load. For the flexible operation, the latter, similar to the static synchronous compensator (STATCOM), is preferred as it provides many supplementary functions like variable var supply, harmonic and unbalance compensations, etc.

Considering the low load factor of the rural load, the most part of generated energy is simply lost through dump load, though few such plants are reported to use the excess energy in battery charging and water heating. In order to utilize the power generated from the MHP system optimally, an effective storage medium is required for storing the surplus energy, which can subsequently be reused during the peak load and time when there is insufficient flow of water. There is wide scale research/practice of employing battery and other emerging technologies with wind/photovoltaic (PV) system [5]-[9], which can also be applicable with MHP. Lead acid battery is somewhat matured and the tested technology in this regard. However the cost, size, and the disposal are the constraining factors for its use in stand-alone mode in remote areas. Further, frequent maintenance requirements, limited charging and discharging cycles are also the bottleneck pertaining to its technology, and hence, have become less attractive options for the future. Among others, recent advancement in fuel cell (FC) and electrolyzer (ELZ) technologies have opened the promising solution by utilizing $\mathrm{H}_{2}$ as the intermediate and long-term storage medium [7]-[11].

An FC power plant is an electrochemical device, which converts the chemical energy into electrical by using $\mathrm{H}_{2}$ and $\mathrm{O}_{2}$ as fuels, whereas the ELZ performs the reversed action. Because of the slow fuel regulation dynamics, the FC cannot provide transient mitigation, necessitating other buffer storages for transient power balance. Integration of ultracapacitor (UC) bank with FC/ELZ is an attractive choice for complete storage domain; long, medium and the short term, providing high efficiency, fast load response, flexible and modular structure for the use of renewable energy system [7], [12]-[14]. This arrangement is capable of providing power balance in such a way that the FC/ELZ system would take care of the steady state and the slow varying demand, and UC would provide the transient compensation.

Integration of FC/ELZ systems with MHP is a new research field and not found in the mainstream research databases, though similar system is reported with other renewables (PV and wind) [6]-[15]. Techno-economical aspects of hydrogen production from the excess hydroelectricity have been reported in [16], and [17] discusses a demonstration project of hydrogen station 
located at the Yakushima island. However, these papers do not cover dynamic electrical model and the reuse of hydrogen in electricity generation. The FC/ELZ/battery system with hybrid power is reported in [5] and [11], while the FC/ELZ/UC system is discussed in [6]-[9]. Multitudes of these studies provide the motivation to introduce such concept in MHP system with change in topology and control structure suitable to it. In these papers, the UC, ELZ, and dc generating sources are connected to the regulated dc bus through the dc-dc converter for each. The ac generating sources are connected to either ac or dc buses with suitable power electronics interfaces. Such a configuration bears the less degree of freedom in control. Especially the dc-dc converter associated with the UC has to regulate both input and output voltages simultaneously. Further, these configurations do not give the clear idea of terminal voltage and frequency regulation when connected to ac-linked hybrid system.

This paper addresses the issues by introducing an alternative topology and control scheme for a stand-alone renewable source with the FC/ELZ/UC as a storage medium. The FC, ELZ, and UC all share a common bidirectional dc-dc converter, thereby relaxing the system with additional burden of the converter and associated controller. Renewable source (in this case MHP) is operated to extract maximum power available, whereas FC/ELZ system is managed to compensate the deficit/excess power in long term and steady state conditions. The UC is responsible for the transient load mitigation of the system during rapid load changing and fault. In addition, it is compatible with the ac interface, and can provide the effective ac voltage and frequency regulation without requiring communication lines.

Beginning with synoptic view of the system to be investigated, the dynamic model of each component is formulated. The complete system is then integrated, simulated, and analyzed using matlab/simulink/simpower for the range of load and input disturbances.

\section{System OVERVIEW}

The objective of the study is to tap the power from the nondispatchable renewable source optimally, while fulfilling the varying load at the same time. For this, a dedicated storage system with suitable configuration, control, and size is required to combine with it. The selection of unit size involves the optimization issues related to cost-driven and site-specific solutions, which is beyond the scope of this paper, so the readers are suggested to consult other sources like [18], [19]. This study considers the technical and the operational requirement while sizing the units.

Fig. 1 shows the schematic diagram of the proposed system, which consists of hydroturbine/IG unit (rated $50 \mathrm{hp}$ ) as main power generating system. Since the turbine is governor free, a secondary unit is required to compensate the system power unbalance. Introduction of FC/ELZ/UC system with proper power electronic interfaces serves the purpose by enabling it to function as the controllable load/source. As shown in the figure, the ELZ and FC are connected with UC bus through a bidirectional chopper allowing the controlled amount of current injected from them. When there is surplus of power, ELZ is switched on producing $\mathrm{H}_{2}$ gas, which then compressed into high pressure and

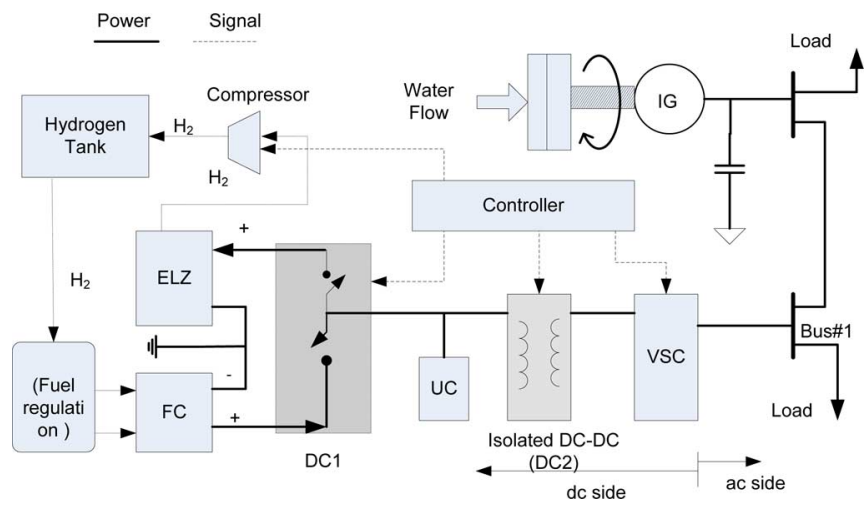

Fig. 1. Layout of the proposed system.

transmitted to the storage tank. Likewise, when the steady state power deficit occurs, FC is turned on to compensate it, with the consumption of $\mathrm{H}_{2}$ from the tank.

It is notable that unlike in the common practice proposed in many studies, this configuration does not require a separate dcdc interface to UC. Instead, the FC/ELZ and UC systems share an isolating bidirectional dc-dc converter to interface with inverter and ac system. The voltage source converter (VSC) serves as the dc-ac interfacing medium providing tight regulation of frequency and the magnitude of the terminal ac voltage. In summary, the proposed scheme replaces the ELC/dump-load unit adopted in [1]-[4] by an electronically controlled FC/UC/ELZ unit, thereby providing self-sustainable power solution for wide range of operating conditions.

While sizing the units, it is roughly estimated that the generation and the demand of energy would match in long term by using $\mathrm{H}_{2}$ medium, with no need of importing it. The maximum load of the system is kept equal to the rated capacity of IG. Assuming the minimum power from IG in adverse condition as $20 \%$ of its rated capacity, an FC with $30 \mathrm{~kW}$ would be able to supply the remaining steady state quota of maximum demand. Similarly, the size of ELZ is selected considering the extreme situation of consuming rated power from IG with all loads OFF, which would make the rating of ELZ about $40 \mathrm{~kW}$. As the system demands, rating of the other components (DC1, DC2, and VSC) are selected as $40 \mathrm{~kW}$ for each.

\section{MOdEl Formulation}

The primary subsystems involved in the proposed system are: MHP, FC, ELZ, and UC. These elements are electrically connected with respective buses and load via suitable power electronics interfaces. Average modeling of the power electronics converters and the dynamic modeling of the individual components are presented in the following sections.

\section{A. IG and Turbine}

The detailed dynamic model of IG can be found in many technical papers and books [20]. Depending upon the requirements of the study, modeling is performed in different reference axes. For the dynamic and transient study, $d-q$ based modeling either in fixed or synchronously rotating axes, are 
incorporated. This study utilizes the built-in model available in the matlab/simulink, which consists of the fixed axes $d$ - $q$ equivalent circuit model, including the effect of the magnetic saturation, appropriate for the study [21]. The standard fifth-order dynamic equations associated with the IG are presented as [3]

$$
\begin{aligned}
\frac{d}{d t}[i] & =[L]^{-1}\left\{[v]-[R][i]-\omega_{r}[G][i]\right\} \\
\frac{d}{d t} \omega_{r} & =\frac{P_{n}}{2 J}\left(T_{m}-T_{e}\right)
\end{aligned}
$$

where

$$
\begin{aligned}
& {[R]=\operatorname{diag}\left[\begin{array}{llll}
R_{s} & R_{s} & R_{r} & R_{r}
\end{array}\right]} \\
& {[v]=\left[\begin{array}{llll}
v_{d s} & v_{q s} & v_{d r} & v_{q r}
\end{array}\right]^{T}} \\
& {[i]=\left[\begin{array}{llll}
i_{d s} & i_{q s} & i_{d r} & i_{q r}
\end{array}\right]^{T}} \\
& {[L]=\left[\begin{array}{cccc}
L_{s}+L_{m} & 0 & L_{m} & 0 \\
0 & L_{s}+L_{m} & 0 & L_{m} \\
L_{m} & 0 & L_{s}+L_{m} & 0 \\
0 & L_{m} & 0 & L_{s}+L_{m}
\end{array}\right]} \\
& {[G]=\left[\begin{array}{cccc}
0 & 0 & 0 & 0 \\
0 & 0 & 0 & 0 \\
0 & -L_{m} & 0 & L_{r}+L_{m} \\
L_{m} & 0 & L_{r}+L_{m} & 0
\end{array}\right]} \\
& T_{e}=\left(\frac{3 n_{p}}{4}\right) L_{m}\left(i_{d r} i_{q s}-i_{d s} i_{q r}\right)
\end{aligned}
$$

where $n_{p}$ refers to the number of pole pair, the suffixes $d$ and $q$ refer to $d$ and $q$ axis (in stator reference frame), $s$ and $r$ to stator and rotor, and $m$ to the magnetizing component. The moment of inertia $J$ includes that of turbine and the generator system assuming the stiff coupling between them. The prime-mover model, consisting of governor-free hydraulic turbine, can be represented by (2) similar to the constant dc load motor drive [3], [22]

$$
T_{m}=C_{1}-C_{2} \omega_{r}
$$

where $C_{1}$ is function of water flow rate and the $C_{2}$ is the feedback coefficient of generator speed.

\section{B. Fuel Cell}

The FCs are the static electrochemical devices, which convert chemical energy of fuel into electrical energy. There are various types of FCs; polymer electrolyte membrane FC, solid oxide FC (SOFC), alkaline FC, etc. Among them, the SOFC has been utilized here. An SOFC is effective in high power stand-alone power applications owing to its high efficiency and thermal stability. The energy-conversion efficiency of the SOFC stack can reach up to $65 \%$ and its overall efficiency with combined heat and power (CHP) applications can even reach above 70\% [23]. Further, due to high-operating temperature, the SOFC allows for internal reforming of gaseous fuel inside the FC, which provides the multifuel applicability [24], [25]. There are various models of SOFC, depending upon the scope of interest; highly theoretical based to more application oriented. Among them, the model given in [25] has been utilized in this study, which includes detailed dynamic model considering the diffusion phe- nomena of reactant gases and the double layer charging effect. The chemical reaction taking place at the electrodes is written as

$$
\left.\begin{array}{l}
\text { Anode: } \mathrm{H}_{2}+\mathrm{O}^{2-} \rightarrow \mathrm{H}_{2} \mathrm{O}+2 e^{-} \\
\text {Cathode: } \frac{1}{2} \mathrm{O}_{2}+2 e^{-} \rightarrow \mathrm{O}^{2-}
\end{array}\right\} \text {. }
$$

The dynamics of the reactant's partial pressure involved in the system can be written as

$$
\left.\begin{array}{l}
\frac{V_{a}}{R T_{\mathrm{fc}}} \frac{d}{d t} p_{\mathrm{H}_{2}}=M_{\mathrm{H}_{2}}^{\mathrm{in}}-M_{\mathrm{H}_{2}}^{\mathrm{out}}-\frac{I_{\mathrm{fc}}}{2 F} \\
\frac{V_{a}}{R T_{\mathrm{fc}}} \frac{d}{d t} p_{\mathrm{H}_{2} \mathrm{O}}=M_{\mathrm{H}_{2} \mathrm{O}}^{\mathrm{in}}-M_{\mathrm{H}_{2} \mathrm{O}}^{\mathrm{out}}+\frac{I_{\mathrm{fc}}}{2 F} \\
\frac{V_{c}}{R T_{\mathrm{fc}}} \frac{d}{d t} p_{\mathrm{O}_{2}}=M_{\mathrm{O}_{2}}^{\text {in }}-M_{\mathrm{O}_{2}}^{\mathrm{out}}-\frac{I_{\mathrm{fc}}}{4 F}
\end{array}\right\}
$$

where the $V_{i}$ s are the volume of the electrode side, $p_{i}$ is the partial pressure of the $i$ th species $\left(i=\mathrm{H}_{2}, \mathrm{H}_{2} \mathrm{O}, \mathrm{O}_{2}\right), M_{i}$ is the mass flow rate of $i$ th species, $F$ is the Faraday constant, $I_{\mathrm{fc}}$ is FC current, and the $R$ is the gas constant. Based upon the chemical reactions taken place at cathode and anode, the voltage generated in a cell $\left(V_{\text {cell }}\right)$ can be written by Nernst equation as

$$
V_{\text {cell }}=E_{\text {cell }}-V_{\text {act,cell }}-V_{\text {ohm,cell }}-V_{\text {conc,cell }}
$$

with

$$
\begin{aligned}
E_{\text {cell }} & =E_{o, \text { cell }}-k_{E}\left(T_{\mathrm{fc}}-298\right)+\frac{R T_{\mathrm{fc}}}{2 F} \ln \left\{\frac{p_{\mathrm{H}_{2}} \sqrt{p_{\mathrm{O}_{2}}}}{p_{\mathrm{H}_{2} \mathrm{O}}}\right\} \\
V_{\mathrm{fc}} & =N_{\text {cell }} V_{\text {cell }}, \quad P_{\mathrm{fc}}=V_{\mathrm{fc}} I_{\mathrm{fc}}
\end{aligned}
$$

where $E_{\text {cell }}$ is the Nernst's potential, $V_{\text {act,cell }}$ is cell-activation potential, $V_{\text {con,cell }}$ is concentration potential, $V_{\mathrm{ohm} \text {, cell }}$ is ohmic potential drop, $E_{o, \text { cell }}$ is Gibbs potential, $k_{E}$ is Boltzmann constant, $P_{\mathrm{fc}}$ is power from FC, $N_{\text {cell }}$ is the number of cell in the stack, and $T_{\mathrm{fc}}$ is the operating temperature. Notice that $E_{\text {cell }}$ in (5) consists of reactants' partial pressure dynamics and considered as the open circuit voltage when the value of pressures in (3) are derived at no-load condition. The individual voltage drop term in (4) can be represented by nonlinear and empirical relationship as

$$
\left.\begin{array}{l}
V_{\text {act }, \text { cell }}=\eta_{0}+\left(T_{\mathrm{fc}}-298\right) a+T_{\mathrm{fc}} b \ln I_{\mathrm{fc}} \\
V_{\text {con,cell }}=-\frac{R T_{\mathrm{fc}}}{z F} \ln \left(1-\frac{I_{\mathrm{fc}}}{I_{\text {limit }}}\right) \\
V_{\text {ohm , cell }}=R_{\mathrm{ohm}} I_{\mathrm{fc}}
\end{array}\right\}
$$

where $I_{\mathrm{fc}}$ is the FC current, $I_{\text {limit }}$ is the limiting current, and $\eta_{0}, a, b$, and $R_{\mathrm{ohm}}$ are the parameters of SOFC. To match the required voltage and power level, a stack is designed based upon the parameters given in the Appendix. The $V-I$ curve for the SOFC stack is presented in Fig. 2 with its electrical model in Fig. 3(a). Fig. 2 shows the three regions. Voltage drop across the FC associated with low currents is due to the activation loss inside the SOFC, voltage drop in the middle of the curve (approximately linear) is due to the ohmic loss in the FC stack, and voltage drop at the end of the curve is due to the concentration loss. The electrical model also illustrates the presence of double-layer capacitor $C_{\mathrm{fc}}$, apart from the voltage and nonlinear resistances. 


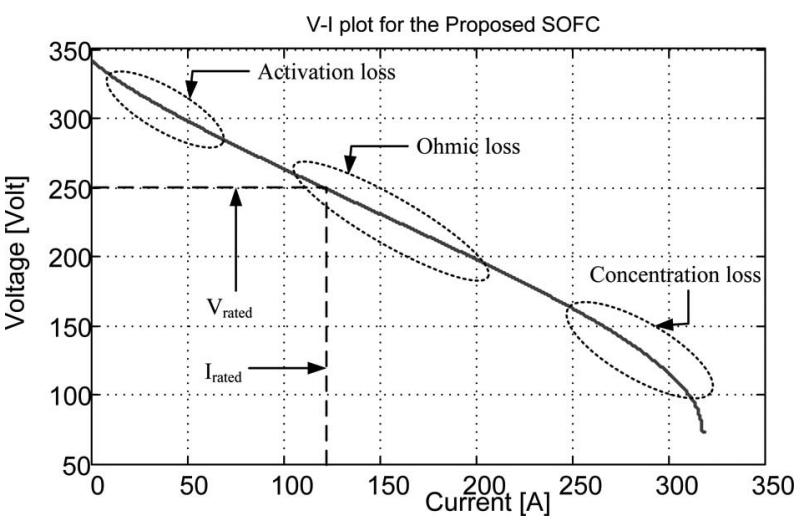

Fig. 2. Static $V-I$ response of the SOFC.

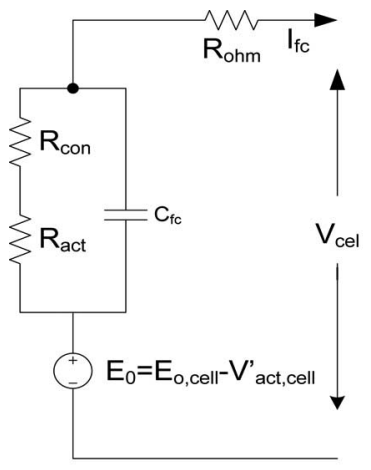

(a)

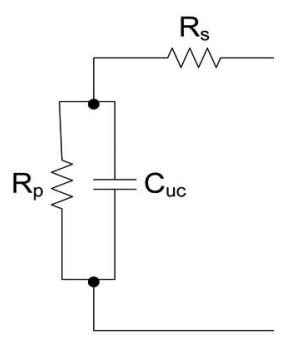

(b)
Fig. 3. Equivalent electrical model of (a) FC and (b) UC.

\section{Ultracapacitor}

The study has used the classical model of UC [see Fig. 3(b)], which consists of an electrical double-layer capacitance $\left(C_{\mathrm{uc}}\right)$, an equivalent series resistance $\left(R_{s}\right)$, and parallel resistance $\left(R_{p}\right)$. The $R_{s}$ represents the charging and discharging resistance, whereas the $R_{p}$ models the leakage effects applicable, mainly, in the long-term energy storage performance of the UC [7], [26].

While designing the desired size of UC, the amount of energy consumed/drawn from the UC bank $\left(E_{\mathrm{uc}}\right)$ in extreme condition is deducted [27], with the specified values of the initial and final value of the UC voltages, as

$$
E_{\mathrm{uc}}=\frac{1}{2} C_{\mathrm{uc}}\left(V_{i}^{2}-V_{f}^{2}\right) .
$$

When the energy is released from the UC, the magnitude of the voltage is decreased and vice versa. To match the desired voltage level and the capacitance, numbers of UC units are assembled in series and parallel fashion based upon the data sheet of Maxwell BMOD0110 [28].

\section{Electrolyzer}

ELZs are the electrochemical devices, which produce hydrogen and oxygen by consuming electricity and water, and broadly characterized as the opposite of the FC system. The modeling consists of different parts: electrochemical part, electrical part, thermal part, and hydraulic part. In this study, the thermal mod- eling is excluded and constant temperature mode is adopted assuming the large time constant of the thermal model. Here, the alkaline (KOH) ELZ model proposed as in [29] and [30] is adopted. Since a unit cell has low value of output potential, a stack is built embedding number of such units in series.

The electrochemical reaction taking place in the ELZ with the application of electricity is written as

$$
\left.\begin{array}{l}
\text { Anode: } 2 \mathrm{OH}^{-}(\mathrm{aq}) \rightarrow \frac{1}{2} \mathrm{O}_{2}(\mathrm{~g})+\mathrm{H}_{2} \mathrm{O}+2 e^{-} \\
\text {Cathode: } 2 \mathrm{H}_{2} \mathrm{O}(\mathrm{l})+2 e^{-} \rightarrow \mathrm{H}_{2}(\mathrm{~g})+2 \mathrm{OH}^{-}(\mathrm{aq})
\end{array}\right\} .
$$

According to the Faraday's law, the hydrogen molar production rate as a function of applied current can be written as

$$
M_{\mathrm{H}_{2}, \text { pro }}=\eta\left(T_{\mathrm{elz}}, J_{\mathrm{elz}}\right) \frac{N_{\mathrm{elz}}}{2 F} I_{\mathrm{elz}}
$$

where $T_{\text {elz }}$ is the temperature of the ELZ, $N_{\text {elz }}$ is the number of cell in a stack. The Faraday efficiency, $\eta$ is the function of current density $\left(J_{\mathrm{elz}}\right)$, and the temperature and represented as

$$
\left.\begin{array}{l}
\eta=\frac{J_{\mathrm{elz}}^{2}}{f_{1}+J_{\mathrm{elz}}^{2}} f_{2} \\
\text { with } f_{1}=50+2.5 T_{\mathrm{elz}}, f_{2}=1-0.00075 T_{\mathrm{elz}}
\end{array}\right\} .
$$

The electrical model of the ELZ is based upon the empirical parameters whose values are deducted from the experiments. The $V-I$ relationship of the alkaline ELZ is written as

$$
\left.\begin{array}{c}
u_{\mathrm{cell}}=u_{0}+I_{\mathrm{elz}} \frac{r_{1}+r_{2} T_{\mathrm{elz}}}{A_{\mathrm{elz}}} \\
\quad+u_{1} \log \left(\frac{t_{1}+t_{2} / T_{\mathrm{elz}}+t_{3} / T_{\mathrm{elz}}^{2}}{A_{\mathrm{elz}}} I_{\mathrm{elz}}+1\right)
\end{array}\right\}
$$

where $u_{\text {cell }}$ is the voltage drop across one ELZ, $u_{0}$ is the thermodynamic cell voltage (function of temperature and pressure), $u_{1}$ and $t_{i} \mathrm{~s}$ are the parameters for the ELZ over voltage, and $r_{i} \mathrm{~s}$ are the parameters of ohmic resistance. The values of respective parameters are shown in the Appendix with static $I-V$ curve as shown in Fig. 4. Clearly, the ELZ can be conceived as a voltage source with internal resistance; both are nonlinear and sensitive to temperature and the current flow through it. While developing the stack of rated value, it is considered that the no-load voltages of FC and ELZ are equal. In other words making $N_{\text {cell }} E_{\text {cell }}=N_{\text {elz }} u_{0}$, there would be continuous static $I-V$ curve for FC/ELZ unit, thereby providing smooth transition between the FC mode to ELZ mode.

The hydraulic part of an ELZ consists of the dynamics of the resultant gases. If we ignore the $\mathrm{H}_{2}$ leakage rate, the accumulating rate of the $\mathrm{H}_{2}$ inside is the difference between the production and the output rates. Based upon the ideal gas law, the resultant pressure dynamics can be written as

$$
\frac{V_{\mathrm{elz}}}{R T_{\mathrm{elz}}} \frac{d}{d t} p_{\mathrm{H}_{2}, \mathrm{elz}}=M_{\mathrm{H}_{2}, \text { pro }}-M_{\mathrm{H}_{2}, \text { out }}
$$

where $V_{\mathrm{elz}}, p_{\mathrm{H}_{2} \text {, elz }}, M_{\mathrm{H}_{2} \text {,pro }}$ and $M_{\mathrm{H}_{2} \text {,out }}$ are the volume of cathode, partial pressure of hydrogen in cathode, molar hydrogen production rate, and molar hydrogen outflow rate, 


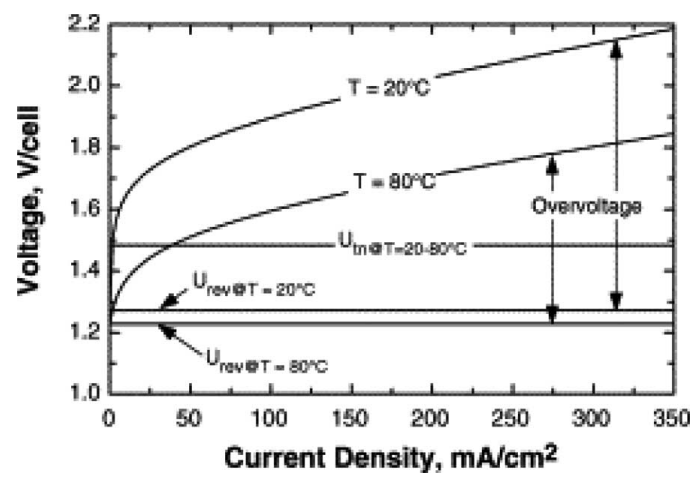

Fig. 4. Static $V-I$ characteristics of an alkaline ELZ [29].

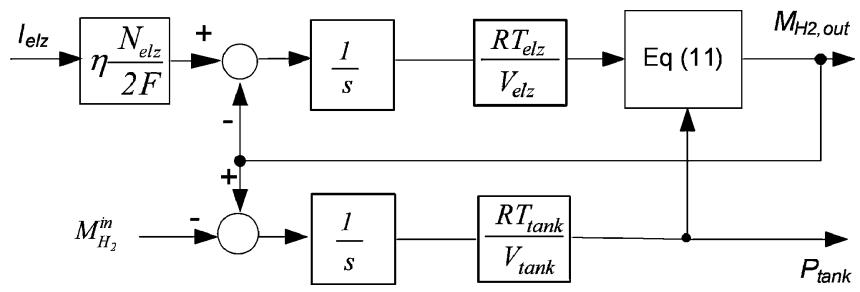

Fig. 5. Block diagram of hydrogen production and storage model.

respectively. At steady state, the outflow rate is maintained equal to the production rate so as to make the pressure constant.

\section{E. Compressor and Tank Model}

According to the polytropic compression model, the relationship between the hydrogen molar flow rate and the compressor power is

$$
\left.\begin{array}{l}
M_{\mathrm{H}_{2}, \text { out }}=\frac{\alpha_{\text {com }}}{w} P_{\text {comp }} \\
w=\frac{k R T_{\mathrm{elz}}}{k-1}\left[\left(\frac{p_{\mathrm{tan} \mathrm{k}}}{p_{\mathrm{elz}}}\right)^{\frac{k-1}{k}}-1\right]
\end{array}\right\}
$$

where $w$ is the polytropic work, $\alpha_{\text {com }}$ is compression efficiency, $k$ is the polytropic coefficient, and $p_{\operatorname{tank}}$ is the pressure of storage tank. Similarly, the stored hydrogen rate in the tank depends upon the difference between the inflow rate and the outflow rate. Thus, the pressure of stored hydrogen in the tank can be written as

$$
\frac{V_{\text {tank }}}{R T_{\text {tank }}} \frac{d}{d t} p_{\text {tank }}=M_{\mathrm{H}_{2}, \text { out }}-M_{\mathrm{H}_{2}}^{\text {in }}
$$

where $T_{\mathrm{tank}}$ and $V_{\mathrm{tank}}$ are the temperature and the volume of hydrogen inside the tank, respectively, and $M_{\mathrm{H}_{2}}^{\mathrm{in}}$ is defined in (3). Based upon the aforementioned equations, the block diagram of hydrogen production and storage is constructed and shown in Fig. 5.

\section{F. Power Electronics Interfaces}

Electrical interconnection of the various renewable sources, storage, and load in a hybrid system necessitate numbers of power electronics interfaces. In this case, three converters are used: 1) dc-dc chopper (DC1) for FC/ELZ current regulation;

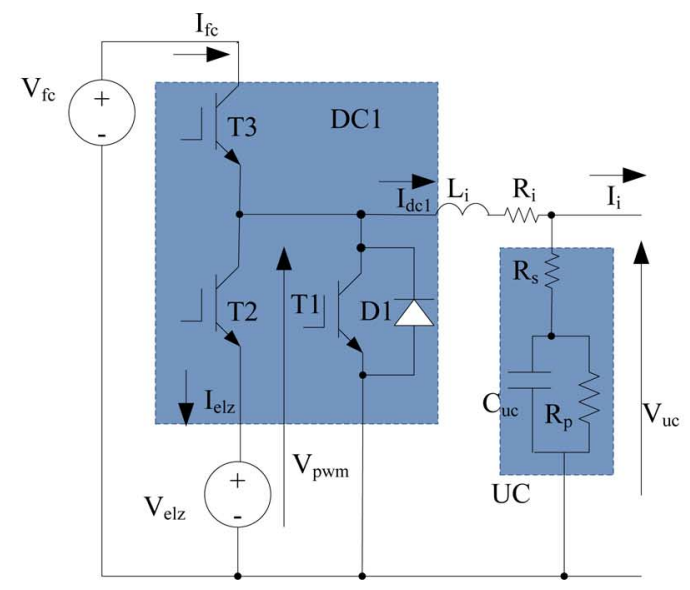

(a)

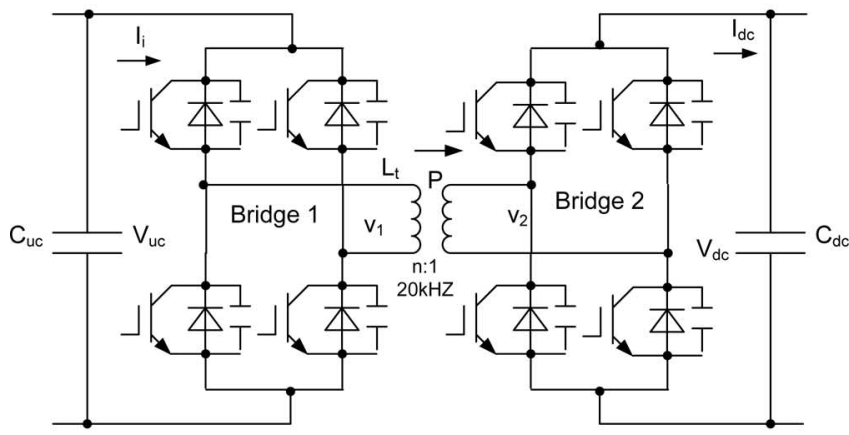

(b)

Fig. 6. Electrical diagram for (a) bidirectional dc-dc chopper, DC1 (b) full bridge dc-dc converter, DC2.

2) dc-dc forward converter (DC2) to regulate the output dc voltage; and 3) VSC for the dc-ac interface. In this research, average model is implemented where the switching function is substituted by the average value of the corresponding duty cycle, assuming the switching period is very small with respect to the system time constant with harmonic effect ignored. These models are well documented in many papers and books [31]-[ 34], therefore, the detailed analysis is ignored here.

The model for the chopper (DC1) is illustrated in Fig. 6(a), employed to regulate the current through the FC/ELZ and $V_{\mathrm{uc}}$. This model resembles the classical two-quadrant dc-dc chopper with minor modification in switching elements to accommodate FC/ELZ control action in the same converter. During the power deficit, the switch pair T3/D1 provide the buck conversion so that FC would supply the compensating power. Conversely, during the surplus of power T2/T1 serve for boost conversion to consume excess power by ELZ. Notice that in boost mode T2 replaces the usual diode to prevent the current path from FC to ELZ. If $d_{2}\left(d_{3}\right)$ is the duty cycle of T2 (T3) and noting that $d_{2}\left(d_{3}\right)$ is activated when $I_{\mathrm{dc} 1}<0\left(I_{\mathrm{dc} 1}>0\right)$, averaged equations for voltage and current can be written as

$$
\left.\begin{array}{l}
I_{\mathrm{fc}}=d_{3} I_{\mathrm{dc} 1}, I_{\mathrm{elz}}=-d_{2} I_{\mathrm{dc} 1} \\
V_{\mathrm{pwm}}=d_{3} V_{\mathrm{fc}}+d_{2} V_{\mathrm{elz}}
\end{array}\right\} .
$$

For the regulation of $V_{\mathrm{dc}}$, full-bridge converter as configured in Fig. 6(b) is implemented because of its: 1) high power 


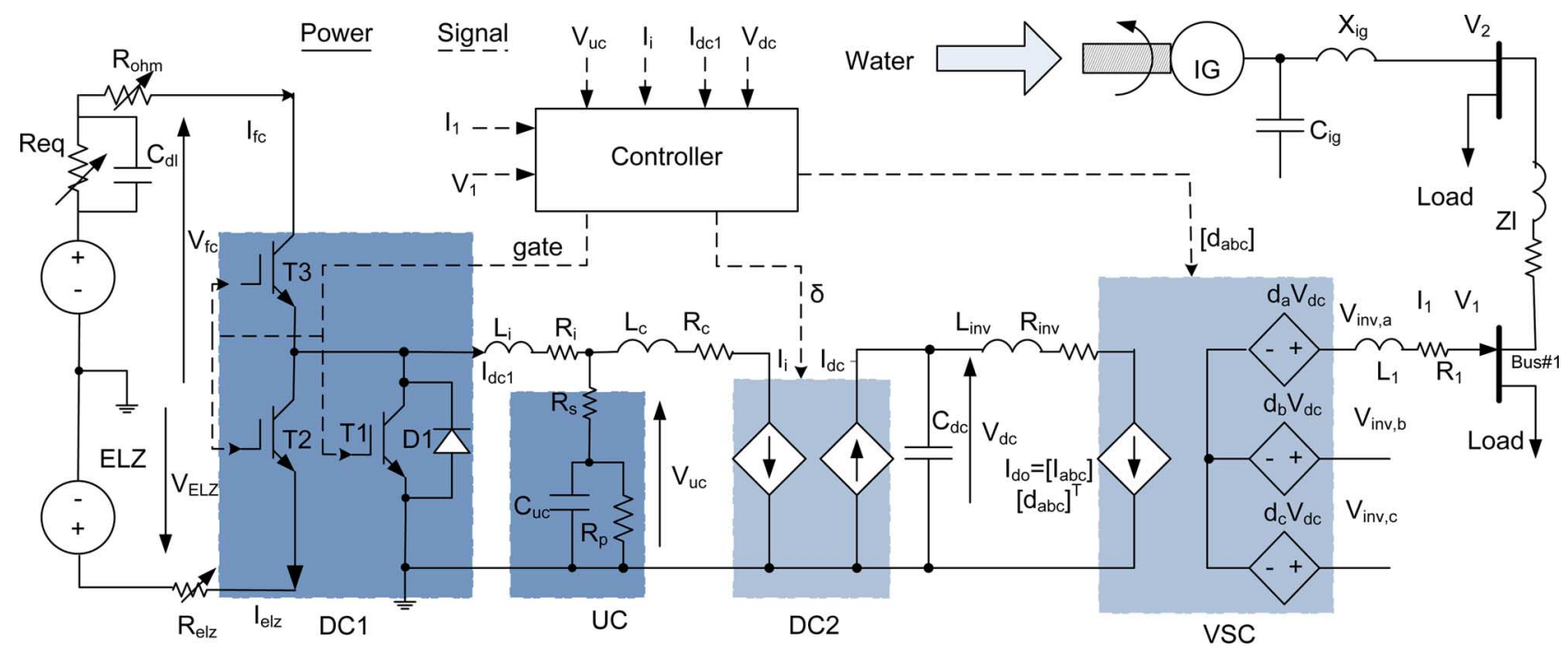

Fig. 7. Electrical layout of the proposed system.

capability; 2) zero voltage/current switching provision for loss reduction; and 3) isolation of FC/UC/ELZ system from the rest of the electrical network. The average model can be deducted from [33], [34], with following equations:

$$
\begin{aligned}
& \left.P=\frac{V_{\mathrm{uc}} V_{\mathrm{dc}}}{2 \pi f_{s} L_{t}}\left(\delta-\frac{\delta^{2}}{\pi}\right), \quad V_{\mathrm{uc}} I_{i}=V_{\mathrm{dc}} I_{\mathrm{dc}}\right\} \\
& \left.I_{i}=\frac{V_{\mathrm{dc}}}{2 \pi f_{s} L_{t}}\left(\delta-\frac{\delta^{2}}{\pi}\right), \quad I_{\mathrm{dc}}=\frac{V_{\mathrm{uc}}}{2 \pi f_{s} L_{t}}\left(\delta-\frac{\delta^{2}}{\pi}\right)\right\}
\end{aligned}
$$

where $\delta$ is the phase shift angle and the other parameters/variables in the earlier equations are defined in Fig. 6(b). Based upon Fig. 6(b) and (14), the model of DC2 is developed as presented in Fig. 7.

VSC is represented by the time-averaged model of threephase dc-ac switching power converter operated through pulsewidth modulation (PWM). Ignoring the high frequency harmonics during the switching, VSC can be seen as a voltage source from ac side and current source from dc side. Dynamic equations governing the instantaneous value of ac side voltage of converter, current exchanged with bus \#1 and the dc voltage can be written, in synchronously rotating $d$ - $q$ frame, as [31], [32]

$$
\left.\begin{array}{rl}
L_{1} \frac{d}{d t}\left[\begin{array}{c}
i_{1 d} \\
i_{1 q}
\end{array}\right] & =\left[\begin{array}{c}
v_{\text {inv }, d} \\
v_{\text {inv }, q}
\end{array}\right]-\left[\begin{array}{cc}
R_{1} & -L_{1} \omega \\
L_{1} \omega & R_{1}
\end{array}\right]\left[\begin{array}{c}
i_{1 d} \\
i_{1 q}
\end{array}\right]-\left[\begin{array}{c}
v_{1 d} \\
v_{1 q}
\end{array}\right] \\
C_{\mathrm{dc}} & =\frac{d}{d t} V_{\mathrm{dc}}=I_{\mathrm{dc}}-\left[\begin{array}{ll}
d_{d} & d_{q}
\end{array}\right]\left[\begin{array}{ll}
i_{1 d} & i_{1 q}
\end{array}\right]^{t}
\end{array}\right\}
$$$$
\left[\begin{array}{l}
v_{d, \text { inv }} \\
v_{q, \text { inv }}
\end{array}\right]=\left[\begin{array}{l}
d_{d} \\
d_{q}
\end{array}\right] V_{\mathrm{dc}}
$$

where $i_{1 j}, v_{1 j}$ and $v_{\text {inv }, j}$ represent the $j(=d, q)$ axes components of current, bus \#1 voltage, and inverter terminal voltage, respectively (see Fig. 7). $L_{1}$ is the equivalent interfacing inductance, $R_{1}$ is the interfacing resistance, $V_{\mathrm{dc}}$ is the dc-link voltage, $\omega$ is the frequency of ac voltage, $C_{\mathrm{dc}}$ is capacitance of dc-side capacitor, and $I_{\mathrm{dc}}$ is the current from the storage system. Equation (15b) describes the relationship of $v_{\text {inv }}$ with $V_{\mathrm{dc}}$ and duty cycles, $d_{d} / d_{q}$ (determined by modulation index, type of PWM and phase angle of rotating vector $\left|v_{\text {inv }}\right|$ ) [31].

\section{G. Controller Model}

An efficient control scheme is necessary to manage the power flow among the hybrid sources in a desired manner. The controller, in this case, is associated with the control action responsible for power electronics interfaces: DC1, DC2, and VSC. As mentioned in the previous sections, DC1 is responsible to regulate the current through FC/ELZ and $V_{\mathrm{uc}}$. Since, $I_{\mathrm{dc} 1}$ is proportional to $I_{\mathrm{fc}}$ or $I_{\mathrm{elz}}$ depending upon the direction of $I_{\mathrm{dc} 1}$, it would be convenient to control single variable. For this, a reference output current for DC1 is generated as

$$
I_{\mathrm{dc} 1}^{*}=\frac{I_{i}}{T_{d} s+1}+k_{p}\left(V_{\mathrm{uc}}^{*}-V_{\mathrm{uc}}\right) .
$$

The first part of (16) ensures that only slow varying and the steady state part of current flows through the FC/ELZ. The current rise time is decided by the parameter $T_{d}$. This value is selected with careful consideration of FC parameters: 1) maximum value of FC current ramp rate and 2) time constant of the fuel regulation block. Likewise, the second term is responsible for regulating UC voltage with the help of proportional control action. Note that the first part in (16) acts as the disturbance feed forward term that enables the effective control action, while second part is associated with the feedback control loop. The design of the controller with $\Delta V_{\mathrm{uc}}$ is based upon the allowed range of $V_{\mathrm{uc}}$. This, in turn, is decided by the $V_{\mathrm{fc}, \min }$ (FC rated voltage), $V_{\text {elz,max }}$ (ELZ rated voltage), $C_{\mathrm{uc}}$, and the effective operating range of the duty cycles $\left(d_{2} / d_{3}\right)$. In this example, range of $V_{\mathrm{uc}}$ is taken from 225 to $275 \mathrm{~V}$ with its nominal value at $250 \mathrm{~V}$. Note also that by making $V_{\mathrm{uc}, \mathrm{nom}} \leq V_{\mathrm{fc}, \min }(250 \mathrm{~V})$, the desired buck/boost operation of DC1 is ensured.

Once the reference current is defined, the direction $I_{\mathrm{dc} 1}$ determines the operating modes of DC1; buck or boost mode. For $I_{\mathrm{dc} 1}>0$, the duty cycle $\left(d_{3}\right)$ produced from the PI action on $\Delta I_{\mathrm{dc} 1}$ generates $s w_{3}$ to turn T3 through the PWM action and 


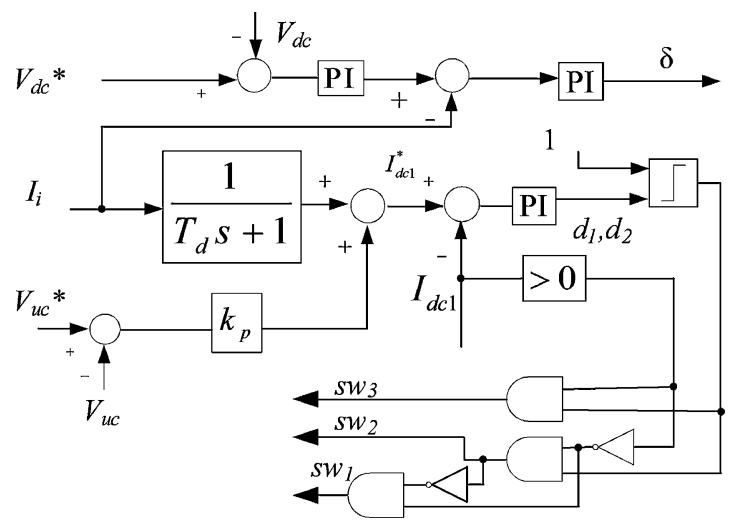

(a)

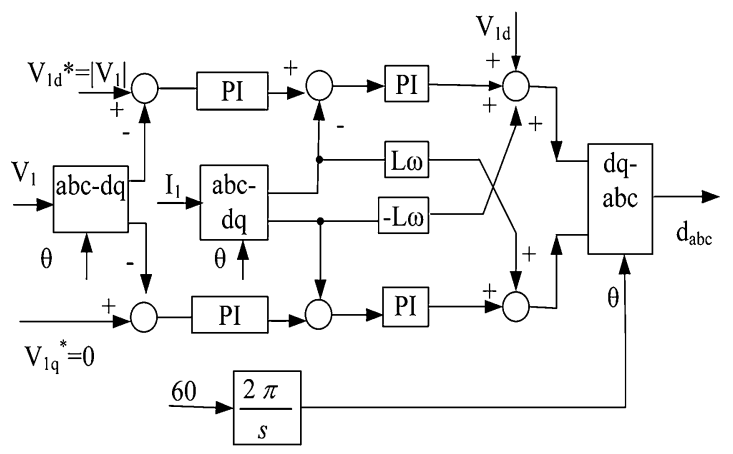

(b)

Fig. 8. Controller block diagram: (a) dc-dc converters and (b) VSC control.

activates FC, while turning T1/T2 off ( with $s w_{2}=s w_{1}=0$ ). Similarly for $I_{\mathrm{dc} 1}<0$, the duty cycle $\left(d_{2}\right)$ produced from the PI action generates $s w_{2} / s w_{1}$ to turn T2/T1 in complementary way through the PWM action and activates ELZ, while turning T3 off (with $s w_{3}=0$ ). By forcing the desired value of $I_{\mathrm{dc} 1}$ (hence, the current flowing through the FC/ELZ), the control action provides direct control over UC voltage without using a separate dc-dc interface.

The purpose of the full-bridge converter is to regulate the output dc voltage, $V_{\mathrm{dc}}$. The regulation is easily achieved by using a PI controller. As shown in Fig. 8(a), the controller has inner loop for current regulation and the outer loop for the voltage regulation, generating the phase shift $(\delta)$ as the controlled variable. The positive value of $\delta$ indicates the power deficit and the negative value indicates the power surplus.

Similarly, the control action of VSC is aimed to regulate the voltage and the frequency of the ac coupling bus. As shown in Fig. 8(b), decoupled controlled action is incorporated in synchronous $d-q$ frame. With tight inner current control loop and the outer voltage regulation loop, the duty cycle for the gate signal is generated. By this strategy, the ac-coupled renewable source is seen as the negative dynamic load to the inverter. Notice that the converter is not employed for dc bus voltage regulation, but for the direct frequency dictation, unlike in usual grid connected VSC control schemes. Consequently, when generated power is greater (less) than load, frequency control action will increase (decrease) $V_{\mathrm{dc}}$ causing to generate negative (positive) $\delta$, and ultimately, the surplus (deficit) power will consume (supply) by ELZ (FC).

From the control action and the circuit configuration of the system, it can be inferred that the FC/UC/ELZ system introduced in the system is independent of the renewable resources connected with it. Hence, the MHP used here is a case, which can be interchanged with other sources like wind and PV power system.

\section{Simulation Results}

The dynamic models of the system, as discussed in the preceding sections, are developed in matlab/simulink environment to test the proposed scheme with the parameters given in the Appendix. The study assumes that the load demand is sufficiently supplied by the IG/UC/FC system. The FC, consisting of array of unit cells, is operated in constant fuel utilization ratio (UR) mode equals to 0.85 . This value of UR justifies the optimum operational mode with higher efficiency and sufficient margin of safety under the different loading conditions [24], [25]. Previously, the FC and ELZ are warmed up and kept in standby mode so that they can quickly follow the command. Further, the $\mathrm{H}_{2}$ is assumed to be available directly from the tank, ignoring the fuel generation and processing dynamics. Hence, a simple first-order system with time constant $5 \mathrm{~s}$ is assumed as fuel regulation block [25]. When the free flow of water hits the turbine, the generator starts smoothly (with the aid of UC charge). Therefore, the ac connection between the inverter and the point of common coupling (PCC) bus is normally made on.

To observe the dynamics of the system, the step change in load and the hydropower input is made. Fig. 9 shows the ac voltage built-up and rotor speed rise up process. For the smooth startup, IG is started as motor, voltage and speed build up gradually, and it shifts into the generator mode. After the stabilization of ac voltage, different step loads are applied in succession; $(30+$ $j 10) \mathrm{kVA}$ at $t=5 \mathrm{~s}$ and $-(15+j 5) \mathrm{kVA}$ at $t=15 \mathrm{~s}$, respectively. Fig. 10 depicts the active power flow dynamics of the system. Before $t=5 \mathrm{~s}$, since there is no load, the generated power is fed to UC and ELZ. For $5 \mathrm{~s}<t<10 \mathrm{~s}$, the generated power is still greater than load $\left(P_{i g}>P_{\text {load }}\right)$, and the excess power continues to flow through the ELZ. At $t=10 \mathrm{~s}$, sudden drop of $P_{i g}$ is observed due to the change in hydroinput causing the power deficit. Current through FC gradually rises toward steady state value to supply the remaining quota of power. Similar type of dynamics is also observed at $t=15 \mathrm{~s}$, when load demand is reduced. At $t=15 \mathrm{~s}$, when $(15+j 5) \mathrm{kVA}$ load is switched off, $\mathrm{UC}$ is temporarily charged by FC because FC cannot decrease the current to the desired steady value immediately. Until FC reaches to newer steady state level, the excess energy has to be consumed by UC. Similar effect can also be observed in other switching instants. In other words, it can be observed that transient unbalance of power at the switching conditions is supplied/consumed by the UC, whereas the steady state part is compensated by the FC or ELZ according to generating/loading conditions. Thus, the fast current transient through FC and ELZ are strategically avoided as desired. For FC, it cannot follow 


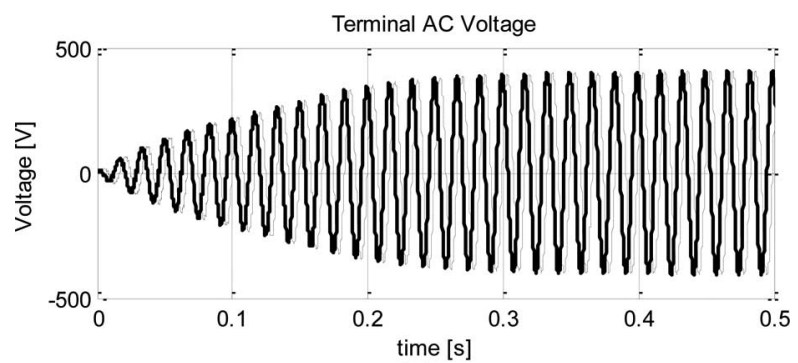

(a)

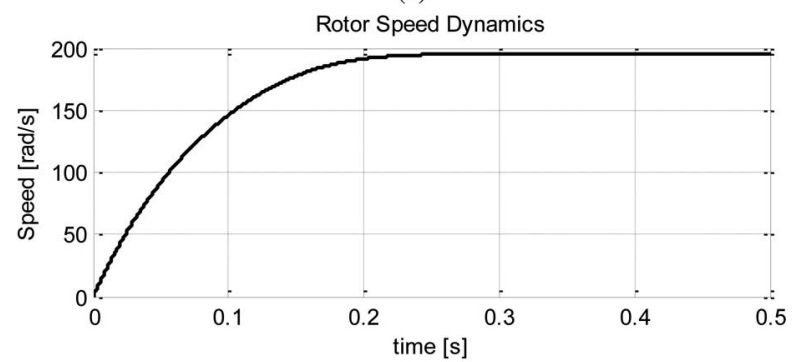

(b)

Fig. 9. Stage of (a) PCC voltage built-up and (b) rotor speed rise up.
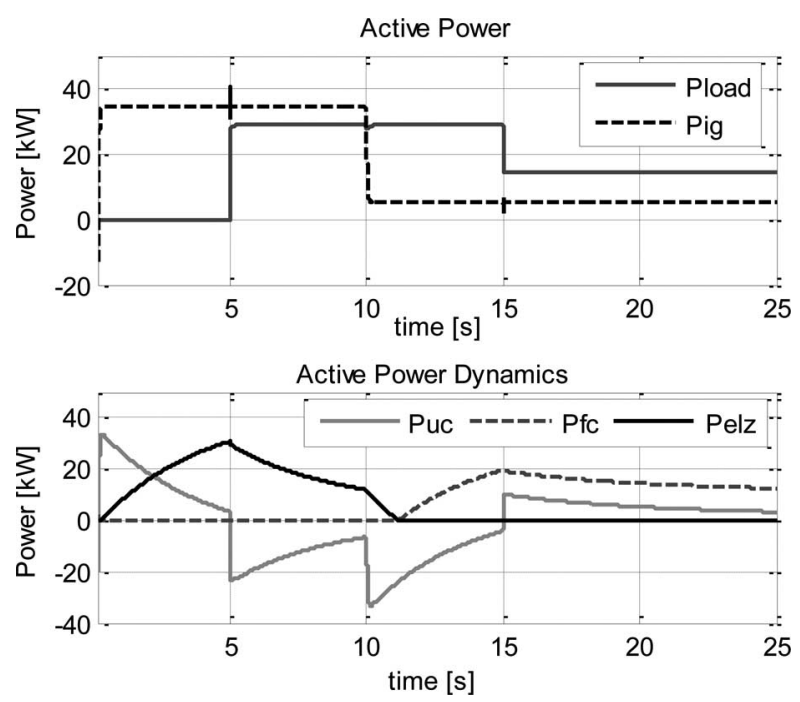

Fig. 10. Dynamics of power flow through different components.

the quick fuel-flow tracking (due to large fuel regulation time) leading to the fuel starvation and undesired pressure drop [23]. Hence, the maximum current ramp rate is limited. Similarly for an ELZ, the fast transient current causes the unwanted pressure deviation affecting undesirably in efficiency of $\mathrm{H}_{2}$ production and its life [35].

Fig. 11 shows the responses of various buses: dc voltage, $\left(V_{\mathrm{dc}}\right)$, ac voltage of PCC bus $\left(V_{1}\right)$, and UC terminal voltage, $\left(V_{\mathrm{uc}}\right)$. As expected, $V_{\mathrm{dc}}$ and $V_{1}$ are regulated quickly around the preset values of 650 and $460 \mathrm{~V}$, respectively. In case of $V_{\mathrm{uc}}$, it is loosely regulated around the present value $(250 \mathrm{~V})$, as it is allowed for wide range of fluctuation (in this case 225$275 \mathrm{~V})$. One of the notable strategies of the control action is that it can regulate 1) UC voltage and 2) FC/ELZ current (thus, indirectly UC current, too) without necessitating the additional bidirectional converter with UC interface. While performing
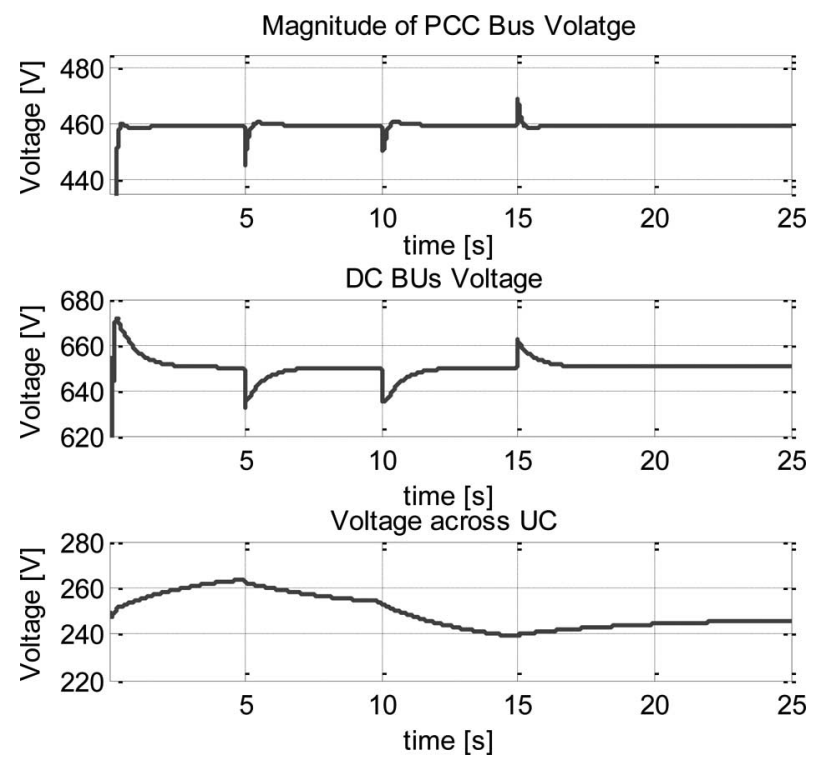

Fig. 11. Dynamics of voltages at different buses.

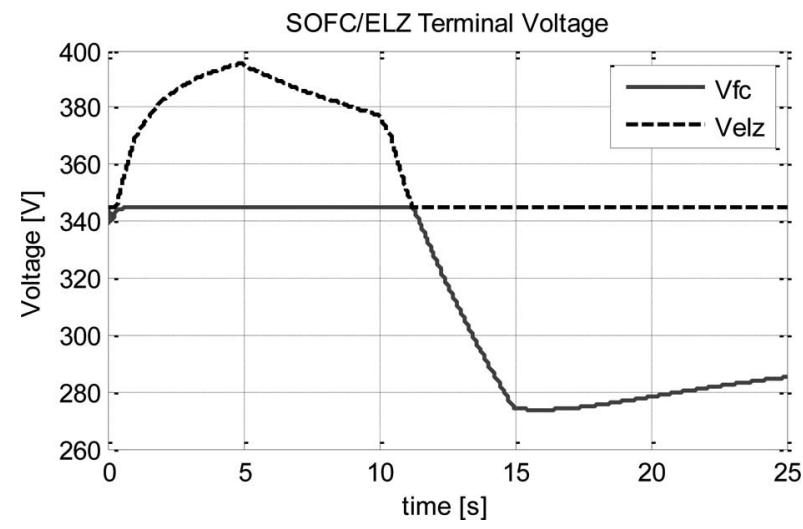

Fig. 12. Response of voltages across FC and ELZ terminal.

the control action, it should, however, be noted that there is tradeoff between these control actions. Since the tight regulation of UC voltage is not required, setting large time constant for the charging/discharging of UC provides the tight control of FC/ELZ current against the varying FC and ELZ voltage (see Fig. 12). Fig. 12 also illustrates that by sizing the FC/ELZ stack such that their open circuit voltages are nearly equal, there would be smooth transition between the buck and boost conversion modes, without voltage discontinuity.

Similarly, Fig. 13 provides the insight into reactants' partial pressure dynamics, which closely follows the response of FC power dynamics as expected. In the absence of UC, the step change in the load would cause step change in the $I_{\mathrm{fc}}$, which leads to fast change in partial pressure of reactants. Because of the slower dynamics of fuel regulation block, the FC system cannot provide the quick compensation for the reactants' partial pressure leading to the adverse effect to the system. Hence, for the stable operation, the time constant of low-pass filter in (16) should be greater than or equal to the time constant of the fuel-regulation system. Likewise, Fig. 14 shows the molar production/consumption rate of hydrogen in ELZ/FC and the 

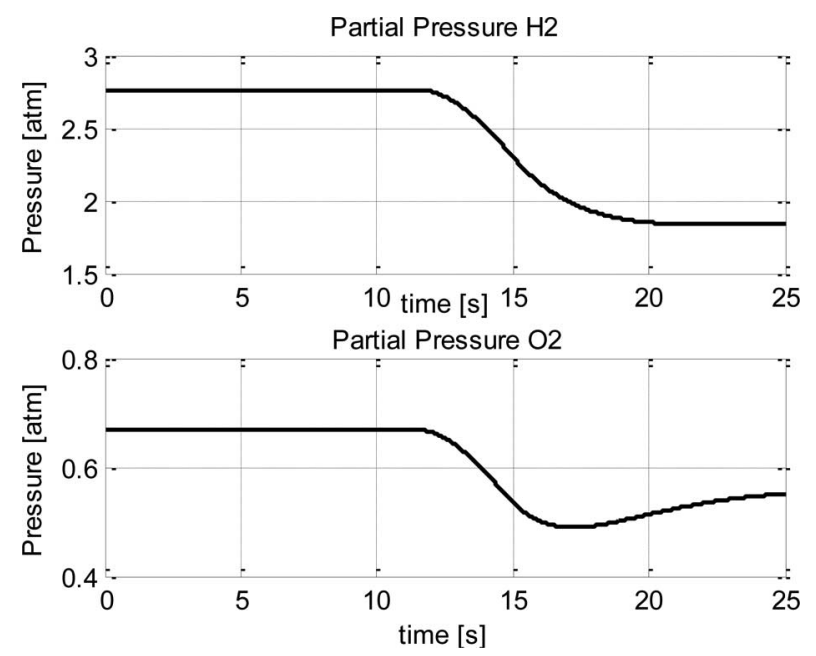

Fig. 13. Dynamics of partial pressure of reactants.
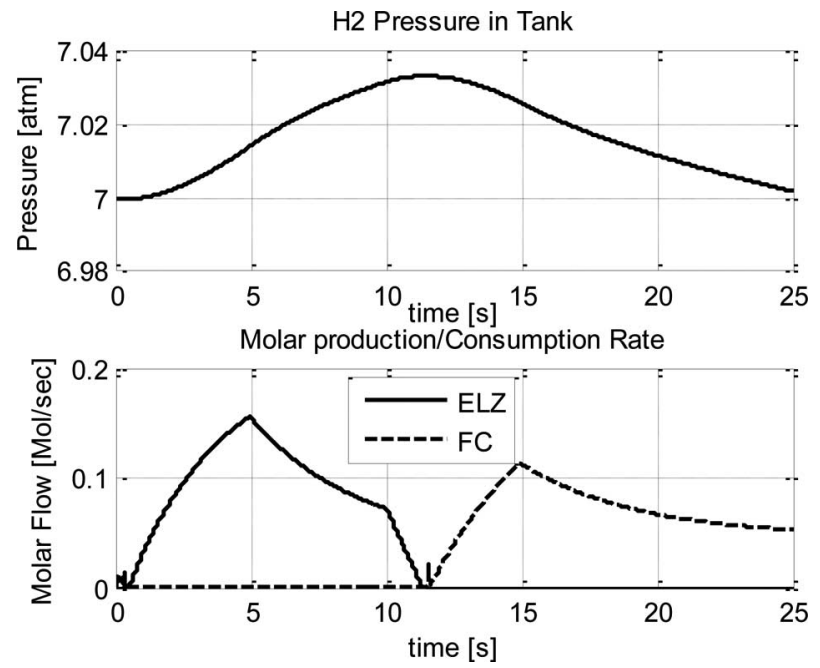

Fig. 14. (a) Pressure change in storage tank. (b) Consumption and production of $\mathrm{H}_{2}$

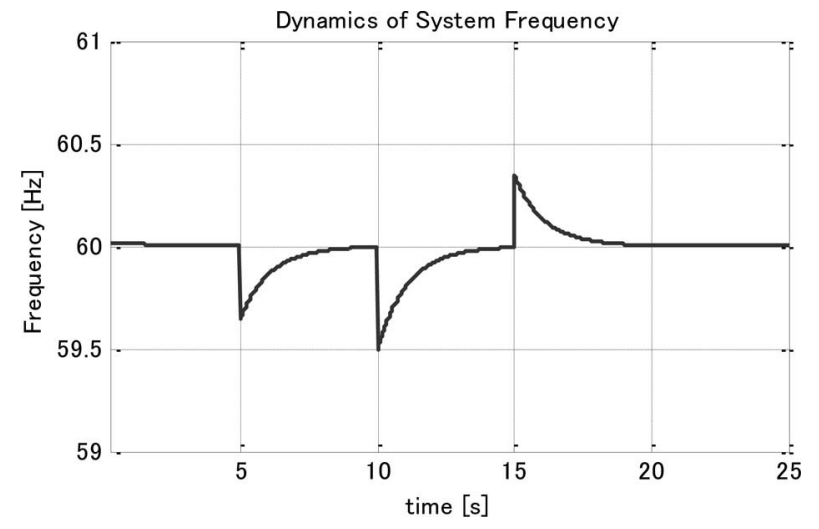

Fig. 15. Variation of system frequency.

pressure dynamics of the storage tank. Finally, Fig. 15 depicts the tight frequency regulation by the inverter control action.

To sum up, these results show that the scheme has successful performance of meeting the requirements. DC1 regulates the UC voltage and the FC/ELZ current, DC2 regulates the dc-bus voltage, and the VSC regulates the frequency and the voltage of the coupling bus, thereby validating the applicability of the scheme.

\section{CONCLUSION}

This paper investigates the integration of FC/ELZ/UC unit to a stand-alone MHP system by using hydrogen as effective power/energy balance medium. For a long period of time, stand-alone MHP has been adopting ELC/dump-load for instantaneous power balance, with poor utilization of surplus power. Replacement of ELC/dump-load by the FC/UC/ELZ unit addresses the limitations providing the solution for capacity utilization, load leveling and peak load.

In order to investigate the system performance, the system configuration and the control scheme are presented with detailed and large-scaled nonlinear model of various subsystems (FC, ELZ, converters, and IG). The simulation results show that the variables under interest are regulated while fulfilling the operating requirements, thereby validating its applicability to the real system. Major limitation, however, to implement the scheme in real system is the cost effectiveness of the hydrogen technology with FC/ELZ system. With dynamic research and advancement in this field, it can be expected that the economics would be favorable in the future. Likewise, model validation with the real/experimental situation is expected for further insights of the scheme.

\section{APPENDIX}

Parameter used in the study

1) Electrical Network:

$$
V_{\mathrm{dc}}=650 \mathrm{~V}, V_{1}=460 \mathrm{~V}, \omega_{0}=377 \mathrm{rad} / \mathrm{s} .
$$

2) $I G:$

$$
\begin{aligned}
& P_{\text {rated }}=50 \text { hp, } V=460 \mathrm{~V}, L_{l s}=0.0576 \text { p.u., } \\
& r_{s}=0.0175 \text { p.u., } L_{l s}=0.0576 \text { p.u., } R_{r}=0.01029 \text { p.u., } \\
& L_{m}=2.019 \text { p.u., } J=0.20 \text { p.u. and } n_{p}=2 .
\end{aligned}
$$

3) Phoebus Alkaline ELZ.

$$
\begin{aligned}
& P_{\text {elz }, \text { rated }}=40 \mathrm{~kW}, N_{\mathrm{elz}}=280, A_{\mathrm{elz}}=0.25 \mathrm{~m}^{2}, \\
& u_{0}=1.22 \mathrm{~V}, z=2, r_{1}=8.05 \times 10^{-5} \Omega \mathrm{m}^{2} \\
& r_{2}=-2.5 \times 10^{-7} \Omega \mathrm{m}^{2}{ }^{\circ} \mathrm{C}, u_{1}=0.185 \mathrm{~V}, \\
& t_{1}=-1.002 \mathrm{~A}^{-1} \mathrm{~m}^{2}, t_{2}=8.424 \mathrm{~A}^{-1} \mathrm{~m}^{2}{ }^{\circ} \mathrm{C}, \\
& t_{3}=247.3 \mathrm{~A}^{-1} \mathrm{~m}^{2}{ }^{\circ} \mathrm{C}^{2}, T_{\mathrm{elz}}=80{ }^{\circ} \mathrm{C} .
\end{aligned}
$$

4) $\mathrm{SOFC}$ :

$$
\begin{aligned}
& P_{\text {rated,fc }}=30 \mathrm{~kW}, N_{\text {cell }}=285, T_{\mathrm{fc}}=1173 \mathrm{~K}, \\
& P_{a}=3 \mathrm{~atm}, P_{c}=3 \mathrm{~atm}, F=96484.6 \mathrm{C} / \mathrm{mol}, T_{d}=5 \mathrm{~s} .
\end{aligned}
$$

5) UC (Maxwell BMOD0110):

$$
\begin{aligned}
& V_{\max }=16.2 \mathrm{~V}, C=110 \mathrm{~F}, I_{\max }=30 \mathrm{~A}, \\
& \mathrm{ESR}=5.5 \mathrm{~m} \Omega, I_{\text {leakage }}=1.5 \mathrm{~mA} .
\end{aligned}
$$


6) UC stack:

$$
P_{\text {rated }}=40 \mathrm{~kW}, C_{\mathrm{uc}}=32 \mathrm{~F}, N_{s}=17, N_{p}=5 .
$$

\section{REFERENCES}

[1] D. Hunderson, "An advanced electronic load governor for control of micro hydroelectric generation," IEEE Trans. Energy Convers., vol. 13, no. 3, pp. 300-304, Sep. 1998.

[2] R. Bonert and S. Rajakaruna, "Self-excited induction generator with excellent voltage and frequency control," in Proc. IEE Gen. Transmiss. Distrib., vol. 145, no. 1, Jan. 1998.

[3] B. Singh, S. S. Murthy, and S. Gupta, "Analysis and implementation of an electronic load controller for a self-excited induction generator," Inst. Elect. Eng. Trans. Gen. Transmiss. Distrib., vol. 151, no. 1, pp. 51-60, Jan. 2004

[4] J. M. Ramirez and T. M. Emmanuel, "An electronic load controller for the self-excited induction generator," IEEE Trans. Energy Convers., vol. 22, no. 2 , pp. 546-548, Jun. 2007.

[5] C. V. Nayar, S. J. Phillips, W. L. James, T. L. Pryor, and D. Remmer, "Novel wind/diesel/battery hybrid energy system," Sol. Energy, vol. 51, no. 1, pp. 65-78, 1993.

[6] M. J. Khan and M. T. Iqwal, "Analysis of small wind-hydrogen standalone hybrid energy system," J. Appl. Energy, vol. 86, pp. 2429-2442, 2009.

[7] O. C. Onar, M. Uzunoglu, and M. S. Alam, "Modeling, control and simulation of an autonomous wind turbine/photovoltaic/fuel cell/ultracapacitor," J. Power Sources, vol. 185, no. 2, pp. 1273-1283, Dec. 2008.

[8] C. Wang and M. H. Nehrir, "Power management of a stand-alone wind/photovoltaic/fuel cell energy system," IEEE Trans. Energy Convers., vol. 23, no. 3, pp. 957-967, Sep. 2008.

[9] M. Little, M. Thomson, and D. Infield, "Electrical integration of renewable energy into stand-alone power supplies incorporating," Int. J. Hydrogen Energy, vol. 32, no. 10/11, pp. 1582-1588, Jul. 2007.

[10] T. F. EI-Shatter, M. N. Eskandar, and M. T. EI-Hagry, "Hybrid PV/fuel cell system design and simulation," Renewable Energy, vol. 27, no. 3, pp. $479-485$, Nov. 2002.

[11] D. Ipsakis, S. Voutetakis, and P. Seferlis, "Power management strategies for a stand-alone power system using renewable energy sources," Int. J. Hydrogen Energy, vol. 34, no. 16, pp. 7981-8095, Aug. 2009.

[12] P. Thounthong, S. Rael, and B. Davat, "Control strategy of fuel cell and supercapacitors association for a distributed generation system," IEEE Trans. Ind. Electron., vol. 54, no. 6, pp. 3225-3233, Dec. 2007.

[13] J. Bauman and M. Kazerani, "A comparative study of fuel-cell-battery, fuel-cell-ultracapacitor, and fuel-cell-battery," IEEE Trans. Veh. Technol., vol. 57, no. 2, pp. 760-769, Mar. 2008.

[14] C. Abbey and G. Joos, "Supercapacitor energy storage for wind energy applications," IEEE Trans. Ind. Appl., vol. 43, no. 3, pp. 769-776, May 2007.

[15] H.-C. Chen, J.-C. Qiu, and C. H. Liu, "Dynamic modeling and simulation of renewable energy based hybrid power," in Proc. Elect. Utility Deregulation Restruct. Power Technol., 2008, pp. 2803-2809.

[16] Z. Yumurtaci and E. Bilgen, "Hydrogen production from excess power in small hydroelectric installations," Int. J. Hydrogen Energy, vol. 29, no. 7, pp. 687-693, Jul. 2004.

[17] T. Kai, Y. Uemura, H. Takanashi, T. Tsutsui, T. Takahashi, Y. Matsumoto, K. Fuji, and M. Suzuki, "A demonstration project of the hydrogen station located on Yakushima Island-Operation and analysis of the station," presented at Int. Symp. Solar-Hydrogen-Fuel Cells 2005, Oct. 2007, pp. $3519-3525$.

[18] J. K. Kaldellisa, E. Kondilib, and A. Filiosc, "Sizing a hybrid wind-diesel stand-alone system on the basis of minimum long-term electricity," $J$. Appl. Energy, vol. 83, no. 12, pp. 1384-1403, Dec. 2006.

[19] S. Diafa, G. Nottona, M. Belhamelb, M. Haddadic, and A. Louchea, "Design and techno-economical optimization for hybrid PV/wind," $J$. Appl. Energy, vol. 85, no. 10, pp. 968-987, Oct. 2008.

[20] P. C. Krause, Analysis of Electric Machinery., vol. 85, San Francisco CA: Wiley-IEEE Press, 2002.

[21] MATLAB SimPowerSystems for use with Simulink user. (2009, Sep.). [Online]. Available: http://www.mathworks.com/access/helpdesk/help/ pdf_doc/physmod/powersys/powersys.pdf
[22] J. S. Gulliver and E. A. Roger, Hydropower Engineering Handbook. New York: McGraw-Hill, 1991.

[23] Fuel Cell Handbook, 6th ed. Alexandria, VA: EG \& G Services, 2002.

[24] K. Eguchia, H. Kojob, T. Takeguchia, R. Kikuchia, and K. Sasaki, "Fuel flexibility in power generation by solid oxide fuel cells," Solid State Ionics, vol. 152/153, pp. 411-416, Dec. 2002.

[25] C. Wang and H. Nehrir, "A physically based dynamic model of solid oxide fuel cells," IEEE Trans. Energy Convers., vol. 22, no. 4, pp. 887-897, Dec. 2007.

[26] R. L. Spyker and R. M. Nelms, "Analysis of double-layer capacitors supplying constant power loads," IEEE Trans. Aerosp. Electron., vol. 36, no. 4, pp. 1439-1443, Oct. 2000.

[27] C. Abbey and G. Joos, "Supercapacitor energy storage for wind energy applications," IEEE Trans. Ind. Appl., vol. 43, no. 3, pp. 769-776, May 2007.

[28] "Electric Double Layer Capacitor: BOOSTCAP_Ultracapacitor," Maxwell Technologies. (2007). [Online]. Available: http://www.maxwell. com/ultracapacitors/datasheets/DATASHEET_16V_series_1009363.pdf

[29] Ø. Ulleberg, "Modeling of advanced alkaline electrolyzers: A system simulation approach," Int. J. Hydrogen Energy, vol. 28, no. 1, pp. 21-33, Jan. 2003.

[30] T. Zhou and B. Francois, "Modeling and control design of hydrogen production process for an active hydrogen/wind hybrid power," Int. J. Hydrogen Energy, vol. 34, no. 1, pp. 21-30, Jan. 2009.

[31] Power electronics Handbook. New York: Academic Press Series, 2000

[32] Z. Ye. "Modeling and control of parallel three-phase PWM converters," Ph.D. dissertation, Virginia Polytech State Univ., Blacksburg, 2001.

[33] S. Inoue and H. Akagi, "Bi-Directional DC/DC converter for an energy storage system," in Proc. Appl. Power Electron. Conf., Feb. 25/Mar. 1, 2007, pp. 761-767.

[34] D. Doncker, R. W. Divan, and M. H. Kheraluwala, "A three-phase softswitched high power density DC/DC converter for high power applications," IEEE Trans. Ind. Appl., vol. 27, no. 1, pp. 63-73, Jan. 1991.

[35] A. Bergen, L. Pit, A. Rowe, P. Wild, and N. Djilali, "Transient electrolyser response in a renewable-regenerative energy system," Int. J. Hydrogen Energy, vol. 34, no. 1, pp. 64-70, Jan. 2009.

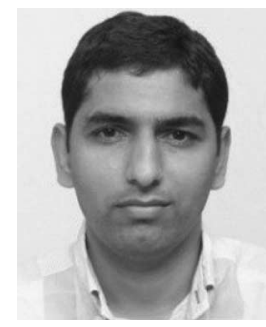

Netra Gyawali (S'08) received the B.E. degree in electrical engineering from the Institute of Engineering (IOE), Tribhuvan University, Kathmandu, Nepal, in 1999 and the M.E. degree in electrical engineering in 2008 from Kyoto University, Kyoto, Japan, where he is currently working toward the Doctoral degree in electrical engineering.

From 2001 to 2005, he was a Lecturer at IOE. His research interests include power electronics, renewable and alternative energy, distributed energy resources, microgrid, energy storage technology.

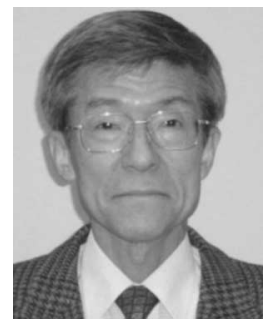

Yasuharu Ohsawa (M'78) received the B.S., M.S and Dr. Eng. degrees in electrical engineering all from Kyoto University, Kyoto, Japan in 1969, 1971, and 1982, respectively.

He joined the Department of Electrical Engineering, Kyoto University as a Research Associate in 1972. After serving as an Assistant Professor and an Associate Professor in the University of Tsukuba, and as an Associate Professor and the Professor in Kobe University, he is currently a Professor in Kyoto University. His main research areas include stability analysis and stabilizing control of electric power systems and application of energy storage in power systems. 